\title{
GESTIÓN DE LAS CIUDADES EN LA ERA DE LA INFORMACIÓN
}

\author{
PAZ BENITO DEL POZO ${ }^{1}$
}

Este libro ${ }^{2}$ coloca el debate sobre la ciudad en primer término dentro del contexto de la economía global y las coordenadas que definen la nueva era informacional, sobre la que Manuel Castells ha reflexionado en profundidad en obras anteriores y bien conocidas. Pero aquí los autores, un urbanista y un sociólogo, van más alla en lo que respecta al papel de las ciudades en el tercer milenio.

La obra empieza por analizar la relación compleja entre los fenómenos de difusión de la innovación tecnológica y el florecimiento de las denominadas industrias de nueva o alta tecnología con el hecho metropolitano, realidades todas que los autores vinculan de manera muy estrecha unas con otras al afirmar que existe una continuidad histórica en la localización de la innovación en torno al poder económico, científico y político de las grandes ciudades. Éstas siguen siendo los catalizadores del progreso, si bien la lógica dominante impone una localización suburbana a los centros de innovación tecnológica industrial que supone un nuevo desafío a la propia ciudad.

A pesar de la crisis de la ciudad, tan analizada hace una década, las grandes urbes, y aún las ciudades medias, siguen siendo un foco de atracción de primer orden para nuevas actividades productivas orientadas unas veces hacia la reconversión o el rejuvenecimiento del tejido industrial y otras hacia la diversificación de éste. En cualquier caso, las ciudades ganan, sobre todo aquellas capaces de abanderar iniciativas que se traduzcan en una mejora de imagen, mayor competitividad productiva y más alta calidad de vida.

Outra aportación de sumo interés de la obra que comentamos se refiere al análisis de las ciudades como actores políticos. En efecto, la ciudad adquiere un protagonismo cada vez mayor tanto en la vida política como económica, social, cultural y mediática, siendo capaz de articular entre sí las administraciones públicas (locales y otras) y los distintos elementos de la sociedad civil a través de la acción colectiva y conjunta. En Europa cunden los ejemplos de ciudades com proyectos de revitalización integrales (en España destacan Barcelona y Bilbao), pero también en otros continentes, sobre todo en Asia (Seúl, Hong Kong, Singa-

\footnotetext{
1 Departamento de Geografía. Universidad de León.

2 BORJA, J. y CASTELLS, M., Local y Global. La gestión de las ciudades en la era de la información. Taurus, Madrid, 1997, 418 págs.
} 
pur, Shangai...). En Estados Unidos, ciudades como Los Ángeles, San Francisco o Seattle también se movilizaron para compatibilizar el crecimiento económico y el desarrollo urbano con la lucha contra la degradación medioambiental, las desigualdades sociales y la inseguridad ciudadana.

Este impulso que adquieren las ciudades comprometidas com su propio futuro, requiere, a su vez, de un gobierno local promotor, es decir, un gobierno que comcentre esfuerzos en proyectar hacia el exterior una imagen fuerte y positiva de la ciudad, buscando la concertación con otras administraciones públicas y la cooperación com otras administraciones públicas y la cooperación público-privada, sin olvidar su promoción interna, encaminada a reforzar la identificación de sus ciudadanos con la nueva imagen y funcionalidad de la ciudad. Los gobiernos locales deben responder a los retos de participación ciudadana, cooperación social e integración de las políticas urbanas, lo que impone la obligación de asumir lo que los autores denominan innovación democrática. Dicha tarea se concretaría en la asunción de competencias y funciones a nivel local que permitan la aplicación de políticas integradas.

En definitiva, y tal como subrayan Borja y Castells, en un momento histórico caracterizado por la globalización de la economía y las políticas de apertura de los mercados, entre otros fenómenos contemporáneos, el proyecto de ciudad basado en un plan estratégico concertado com todos los agentes sociales representa una oportunidad democrática, pues ofrece una respuesta integrada desde el lugar mismo donde se plantean los problemas y abre ante el ciudadano la perspectiva de reconstruir el sentido de la ciudad, del territorio, recuperando una identidad con lo local perdida o cuando menos, profundamente dañada.

En la escena mundial las ciudades tienden a organizarse en redes como un mecanismo de inserción en un entorno internacional y una estrategia de mejora de la competitividad. Los elementos más positivos de estas redes se pueden sintetizar en:

- Las redes permiten a sus miembros la inserción en un sistema de relaciones superior.

- Las redes permitem el acceso a grandes volúmenes de información.

- Las redes se consolidan como un mecanismo de desarrollo de la política exterior.

- Las funciones de liderazgo e imagen se refuerzan.

- En un mundo sometido a cambios continuos, las redes permiten una cierta permanencia en el tiempo de las líneas de actuación.

Pero el funcionamiento en redes también entraña problemas y dificultades. La diversidad de situaciones y organización de las distintas ciudades puede generar conflictos de intereses que ponen en riesgo la continuidad y resultados de la cooperación entre ciudades. Con frecuencia los principales beneficiados de las redes son los miembros más potentes y activos, hecho que distorsiona las relaciones internas.

Las ciudades, en fin, tienen un complejo y apasionante reto ante sí: entrar en el nuevo milenio com un planteamiento de organización y gestión más eficaz, democrático y global. 